\title{
Analysis of Behavior of Windows in Terms of Saving Energy in Extreme Cold Weather Climes of Iran
}

\author{
Saeed Banihashemi, Mahmoud Shakouri Hassanabadi, and Aidin Nobahar Sadeghifam
}

\begin{abstract}
It has been recognized that windows, the thermally weakest link in the building fabric, are thermal holes. This paper aims at analyzing the performance of double-glazed windows in terms of total saved heating and cooling loads in the extreme cold weather throughout the year and in different orientations. A four-story building representing the conventional type of residential apartments in Iran for city of Ardabil which is the representative of extreme cold climate was selected for simulation. Four physical properties of U-factor, solar heat gain coefficient (SHGC), visible transmittance (VT) and emissivity along with the orientation were the factors taken into consideration for simulation. It was concluded that in Ardabil, as a heating load dominant city, the merits of utilizing double glazed windows lie in their savings in terms of heating load not cooling load. In fact, using double glazed windows in extreme cold climates imposes extra cooling load on buildings which of course is inconsequential in comparison with the saved heating load.
\end{abstract}

Index Terms-Window, energy performance, heating load, cooling load.

\section{INTRODUCTION}

Despite widespread calls for reducing in energy usage and natural resources exploitation, Sustainability and environmental issues are still among those cases that have received little consideration. When sustainability issues are considered, it is usually with respect to energy consumption or the choice of materials [1]. Energy consumption is the main responsible for emissions of greenhouse worldwide. In Iran, up to $99 \%$ of energy is generated from fossil fuels which have a direct impact on continuously increasing carbon emissions [2]. In the meanwhile, residential buildings amounted to $30 \%$ of the country's total energy consumption [3]. In addition, the average quantities of the thermal loss in the present situation of the country's residential buildings are: walls $35 \%$, floors $7.5 \%$, ceilings $7.5 \%$ and windows $50 \%$, [4].

Windows, providing natural light, ventilation and weather protection, are very important components of residential and commercial buildings. However, it has been recognized that windows, the thermally weakest link in the building fabric, are thermal holes. They cause valuable heat loss and thermal discomfort, due to very poor insulation characteristic, i.e. high heat-conduction characteristic, of glass. One way to reduce energy losses through windows is to install double-glazed windows [5]. Window energy performance

Manuscript received March 9, 2012; revised September 20, 2012.

The authors are with the Department of Construction Management at Universiti Teknologi Malaysia (e-mail: sbnseyed2@live.utm.my; shmahmoud3@live.utm.my; aidin_sa1983@yahoo.com). depends upon window properties as well as the climatic conditions of the location and window's orientation. The values of incident solar radiation and, hence, the values of solar heat gain that are useful in offsetting house heating loads, actually depend on local climatic conditions and the direction in which the window is installed. Similarly, outdoor temperatures and wind conditions which determine heat losses by transmission and by air leakage are also dependent on location [6].

During the last decade, many scholarly works were done in order to study and analyze the energy performance of windows with respect to different properties. G.F. Menzies and J.R. Wherrett studied on four buildings to rate the comfort and sustainability level based on diverse types of multi-glazed windows by concentration on the energy using emphasizing the importance of architectural design on the multi-glazed windows performance [1]. Persson et al evaluated the different dimension of windows in terms of energy performance for low energy houses during winter and summer by various orientations in Gothenburg. It was illustrated that by reduction in window area, there is a specific enhancement in winter performance energy [7]. Andrea Gasparella et al concluded that windows surface does not have a significant role in winter energy requirements but, on the other hand, solar transmittance is the most effective parameter which conducts the major needs for energy in both winter and summer [8].

In this paper, monthly loads, heating and cooling loads, are used as the basis of comparison. It should be noted that these are heating and cooling loads, not energy loads. These loads determine how much cooling or heating is required to maintain spaces in a building within the thermal comfort band. However, energy consumption depends on the efficiency of the devices used for cooling or heating those spaces and apparently, for the same load, different devices with different efficiencies result in different energy consumptions. Therefore, using cooling or heating load as the basis of comparison shows a more realistic view in terms of the impacts of windows on buildings. This paper aims at analyzing the performance of double-glazed windows in terms of total saved heating and cooling loads in the extreme cold weather throughout the year and in different orientations.

\section{RESEARCH DESIGN}

This paper uses a full scale simulation including climatic data, building type and properties method for analyzing the performance of double-glazed windows in the context of extreme cold weather for Iran. This model is based on the 
assumption that windows have direct impacts on the heating and cooling loads of building, which consequently affects the energy loss and consumption. To limit the scope of this study, it was assumed that the simulated case represents a typical residential building type with common materials used in its envelope in Iran.

TABLE I: PROPERTIES OF SELECTED DOUBLE GLAZED WINDOWS FOR SIMULATION.

\begin{tabular}{ccccc}
\hline Window & U-factor $\left(\mathrm{W} / \mathrm{m}^{2} . \mathrm{K}\right)$ & SHGC & VT & Emissivity \\
\hline Base & 6.00 & 0.56 & 0.72 & 0 \\
W-01 & 1.647 & 0.32 & 0.59 & 0.035 \\
W-02 & 1.760 & 0.22 & 0.32 & 0.022 \\
W-03 & 1.874 & 0.15 & 0.15 & 0.042 \\
W-04 & 1.931 & 0.34 & 0.59 & 0.042 \\
W-05 & 2.044 & 0.21 & 0.46 & 0.022 \\
W-06 & 2.214 & 0.16 & 0.16 & 0.035 \\
W-07 & 2.442 & 0.44 & 0.54 & 0.107 \\
W-08 & 2.555 & 0.3 & 0.42 & 0.035 \\
W-09 & 2.612 & 0.61 & 0.66 & 0.107 \\
W-10 & 2.725 & 0.55 & 0.59 & 0.107 \\
W-11 & 2.839 & 0.27 & 0.38 & 0.035 \\
W-12 & 3.180 & 0.48 & 0.57 & 0.107 \\
\hline
\end{tabular}

TABLE II: CLIMATIC DATA OF ARDABIL.

\begin{tabular}{|c|c|c|c|c|}
\hline City & Month & Dry bulb Temperature & \% humidity & Wind Speed m/s \\
\hline \multirow{12}{*}{ 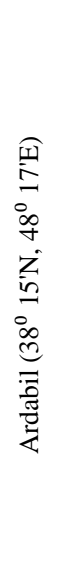 } & Jan & -2.6 & 75 & 1.3 \\
\hline & Feb & -1.1 & 73 & 2.6 \\
\hline & Mar & 3.2 & 73 & 2.8 \\
\hline & Apr & 9.7 & 66 & 2.7 \\
\hline & May & 13 & 70 & 2.1 \\
\hline & Jun & 16.6 & 70 & 2.4 \\
\hline & Jul & 19 & 68 & 3.4 \\
\hline & Aug & 18.5 & 70 & 3.4 \\
\hline & Sep & 15.6 & 73 & 2.4 \\
\hline & Oct & 10.7 & 74 & 2.1 \\
\hline & Nov & 5.3 & 74 & 2.5 \\
\hline & Dec & 0.3 & 74 & 1.7 \\
\hline
\end{tabular}

As a result, a four story building consisting of two units on each floor was selected for simulation representing the conventional type of residential apartments in Iran. The total area of the building is $527 \mathrm{~m} 2$ and the ratio of the total window area to total floor area is $22.8 \%$. It was modeled in Revit Architecture and exported to Autodesk Ecotect Analysis 2011 for energy analysis. A conventional 22cm brick wall with two layers of cement mortar and granite stone on the exterior surface and a layer of plaster on the interior side of the wall is used as the exterior wall of the model. The outer surface of the roof is covered by $10 \mathrm{~cm}$ layer of asphalt which is a common material for covering the roof. For energy simulation, each room in the building was defined as a zone which each zone had its own thermal properties. The thermostat was set between 18-26 oC to provide thermal comfort for the occupants. Four physical properties of U-factor, solar heat gain coefficient (SHGC), visible transmittance (VT) and emissivity were the factors taken into consideration for choosing sample windows for the simulation [9]. Accordingly, one type of single glazed aluminum frame window which is typically used in residential buildings in Iran was selected as the base window and 12 double glazed aluminum frame windows were chosen from the market for comparison purposes (Table I).

In order to determine the performance of fenestration systems accurately, considering a plethora of variables such as building types and their orientations, climatic data of the location in which the windows are used, are essential [10]. Table II shows monthly mean values of climatic data for the selected city. To measure the impacts of various types of windows on the cooling and heating loads, the properties of other components such as walls, roofs etc. were kept fixed and the simulations were run by varying only the properties of windows. In the end, total numbers of 48 simulations were conducted to calculate the monthly loads of the building for Ardabil and four orientations. In order to calculate the impacts of windows on the cooling and heating loads, the simulation results of 12 window alternatives were subtracted from the base window simulation values, resulting in monthly saved heating or cooling load.

\section{ANALYSIS AND DISCUSSION}

The performance of 12 different types of windows in terms of monthly heating and cooling saved loads in the context of Ardabil was investigated through thermal simulation and the results are given in Figs. 1-4. The negative amounts in the Figs represent the saved loads by the windows vis-à-vis the base window and the positive results show the extra loads required to maintain the comfort level of the spaces within the building for occupants.

In all orientations and during cold months, $\mathrm{W}-01$ proved to have the highest saving and $\mathrm{W}-12$ the least. The amount of saving ranges from the minimum of $-177 \mathrm{~kW}$.h for $\mathrm{W}-12$ in the north in April to the maximum of $-4923 \mathrm{~kW}$.h for W-01 in the east orientation in January. Due to the highest U-factor of $\mathrm{W}-12$, heat transfer rate in this window is higher compared to the others which lead to the least amount of saving. In general, in cold seasons, due to the existing large temperature gradient between indoor and outdoor temperature, using a window with low U-factor highly contributes to saving in heating load and prevention of heat loss through fenestration. Therefore, due to the low value of U-factor of all the windows compared to the base window, all the simulated windows performed better than the base window, which contributed to the minimum of 11 to maximum of 39 percent of savings in the saved load for cold months. Ardabil is a heating dominant city in which based on Table II, in 10 out of 12 months of the year, the average dry bulb temperature is below the assumed comfort band. 

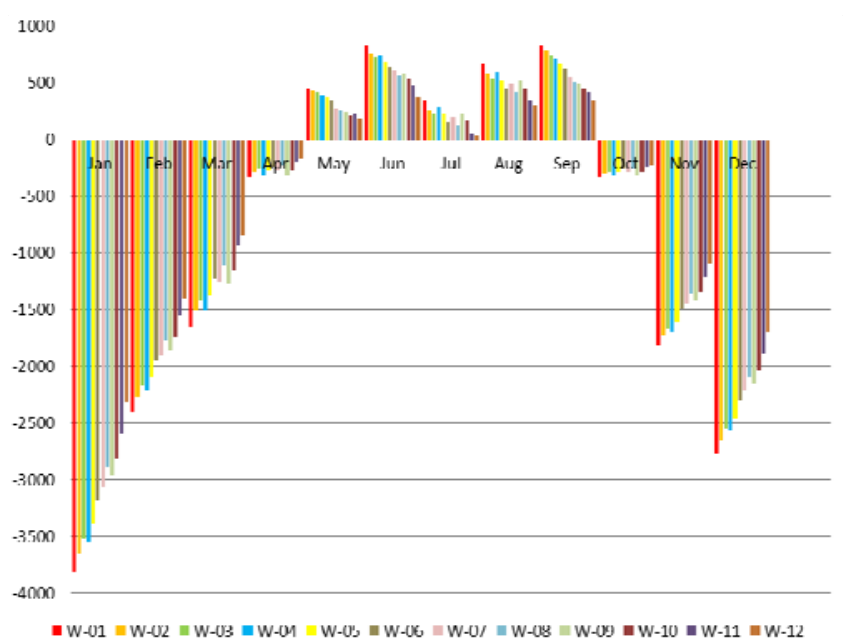

Fig. 1. Monthly load saved [kWh] for the north orientation.

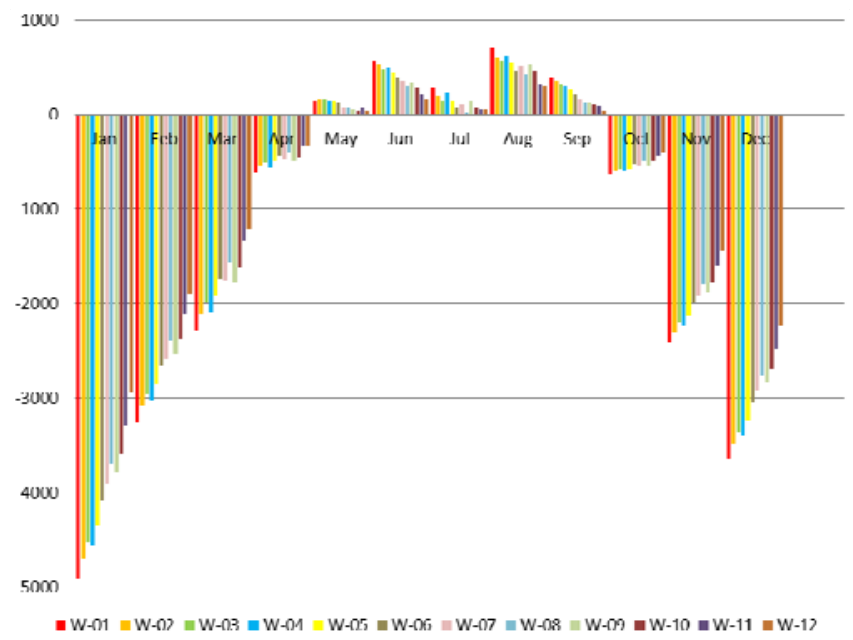

Fig. 2. Monthly load saved [kWh] for the east orientation.

There is a downward trend for the saved heating load in cold months for buildings in Ardabil as the U-factor increases. However, there are some deviations in some points such as $\mathrm{W}-03$ to $\mathrm{W}-04$ and $\mathrm{W}-8$ to $\mathrm{W}-09$. Table III shows that although the U-factors of $\mathrm{W}-04$ and $\mathrm{W}-09$ are higher than $\mathrm{W}-03$ and $\mathrm{W}-08$ respectively but in the latter group, the amount of SHGC is more than two times. The SHGC is the fraction of the heat from the sun that enters through a window. The lower a window's SHGC, the less solar heat it transmits [10]. As the SHGC of a window increases, more incident solar radiation is transmitted into a room and as a result, more energy is required to balance the cooling load. Therefore, in cases of W-04 and W-09, higher SHGC compared to the U-factor plays a more important role in saving heating load.

On the contrary, using double glazed windows with low U-factor do not contribute to any savings for the cooling load in Ardabil for hot months of May-September. Since, on one hand, in hot seasons the outside temperature of buildings in Ardabil rarely exceeds the comfort band and on the other hand, due to the latent loads inside buildings which lead to the interior to be warmer than the exterior, using a window with low U-factor prevents heat transfer from inside to the outside and therefore increases the cooling load in buildings. In case of cooling load, the base window outperforms the other alternatives and this is because of its high U-factor, which leads to a higher heat transfer. Among the 12 types of double glazed windows, W-08 located in the west in July with 0.3 percent and W-01 located in the north orientation in September with 72 percent have the lowest and highest percent increase in the cooling load respectively.

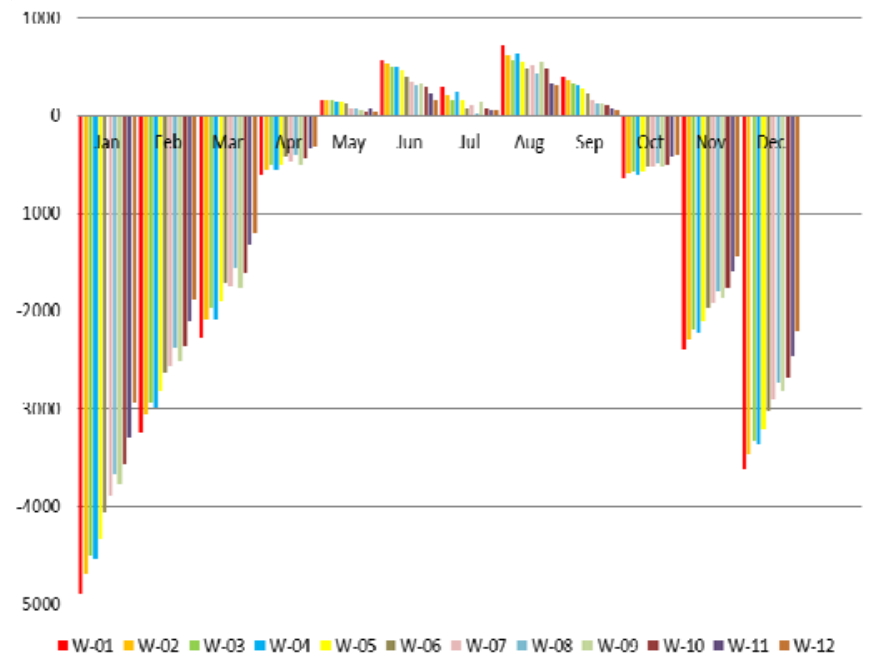

Fig. 3. Monthly load saved [kWh] for the south orientation.

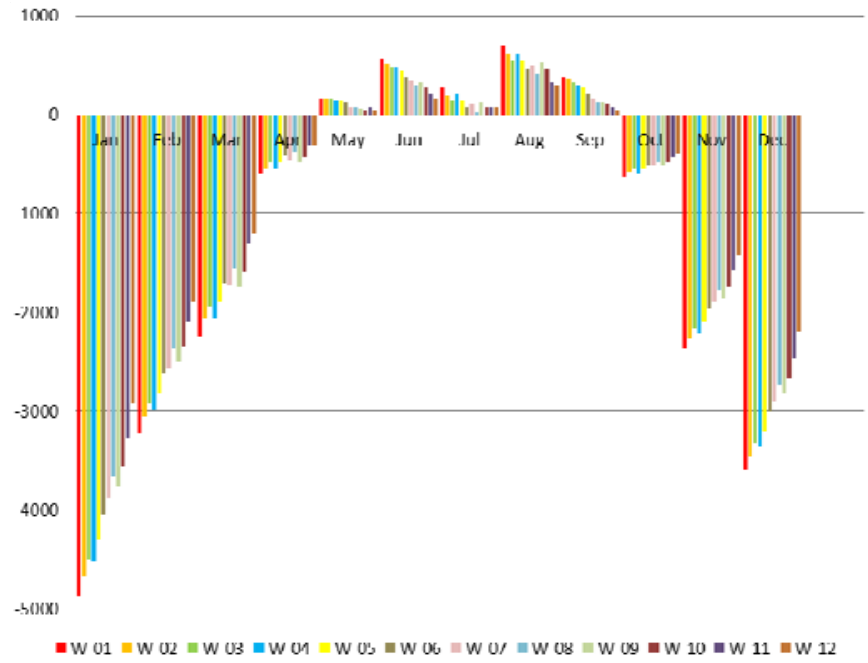

Fig. 4. Monthly load saved [kWh] for the west orientation.

Based on Figs. 1-4, the amount of average saved loads for cold months in comparison with hot months, for the orientations of north, east, south and west are 3, 7, 7 and 7 times greater respectively. In general, the variation in the performance of each type of double glazed window in three main orientations of east, south and west is inconsequential but in the north, since fenestrations are not exposed to the direct solar radiation and the rooms located in that part of buildings are generally cooler than other sides, the efficacy of double glazed windows in terms of saved loads is not as remarkable as those in the eastern, southern and western windows.

\section{CONCLUSION}

In this paper, the behavior of windows with respect to saving energy for Ardabil city which represents the extreme cold climate of Iran was studied. 12 different double-glazed windows chosen from the market were used for comparison 
purposes. It was found U-factor and SHGC are two main properties which play key roles in determining the energy performance of windows. Finally, it was concluded that as a heating load dominant city, the merits of utilizing double glazed windows lie in their savings in terms of heating load. In fact, the amount of extra cooling load imposed by the double glazed windows in comparison with the saved heating load during the cold months is negligible.

\section{REFERENCES}

[1] G. F. Menzies and J. R. Wherrett, "Windows in the workplace: examining issues of environmental sustainability and occupant comfort in the selection of multi-glazed windows," J. Energy and Building, vol. 37, pp. 623-630, 2005.

[2] A. S. Bakhtiari and F. Shahbudaghlou, "Energy consumption in the islamic republic of Iran,” OPEC Review, vol. 24, pp. 211-33, 2000.

[3] Earthtrends. (2011). [Online]. Available: http://earthtrends.wri.org/pdf_library/data_tables/ene3_2005.pdf;

[4] S. Z and S. M, "An energy efficiency plan for the Iranian building sub-sector,” J. Energy Policy, vol. 35, pp. 1164-1171, 2007.

[5] A. Orhan, "Determination of optimum air-layer thickness in double-pane windows," J. Energy and Buildings, vol. 32, pp. 303-308, 2000.

[6] M. C. Singh and S. N. Garg, "Energy rating of different glazings for Indian climates,” J. Energy, vol. 34, pp. 1986-1992 , 2009.

[7] M.-L. Persson, A. Roos, and M. Wall, "Influence of windows size in the energy balance of low energy houses," J. Energy and Buildings, vol. 38, pp. 181-188 2006.
[8] A. Gasparellaa, G. Pernigottob, F. Cappellettic, P. Romagnonic, and P. Baggiod, "Analysis and modeling of window and glazing systems energy performance for a well insulated residential building," $J$. Energy and Buildings, vol. 43, pp. 1030-1037, 2011.

[9] G. Menzies and J. Wherrett, "Multiglazed windows: Potential for savings in energy, emissions and cost," J. Building Services Engineering Research and Technology, vol. 26 pp. 249-258, 2005.

[10] ASHRAE Handbook Fundamentals, American Society of Heating Refrigerating and Air-Conditioning Engineers, Atlanta, 2009.

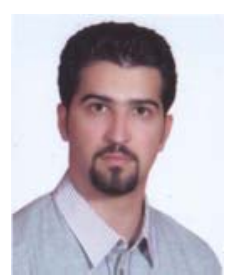

Seyed Saeed Banihashemi was born in Ardabil, Iran in 1985. He received his degree in architecture from Iran in 2008 and started his master degree in construction management at University Teknologi Malaysia in 2010. His research interests are mainly building information modeling, industrialized building system, energy analysis and also green building rating tools. Currently, as a part of his thesis research, he is trying to integrate industrialized building system with building information modeling by virtue of developing IFC algorithms for some prefabricated components.

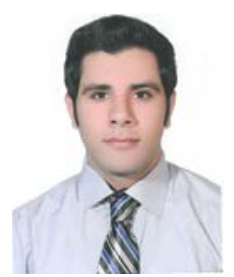

Mahmoud Shakouri Hassanabadi received his degree in architecture from Islamic Azad University, Iran in 2007 and started his master degree in construction management at University Teknologi Malaysia in 2010. His research interests are mainly building information modeling, energy analysis and also improving the performance of buildings with regard to sustainability standards. 